\title{
CLOSE-RANGE PHOTOGRAMMETRY METHOD FOR SF6 GAS INSULATED LINE (GIL) DEFORMATION MONITORING
}

\author{
K. N. Fauzan ${ }^{1}$, D. Suwardhi ${ }^{1}$, A. Murtiyoso ${ }^{2}$, I. Gumilar ${ }^{3}$, T. P. Sidiq ${ }^{3}$ \\ ${ }^{1} 3 \mathrm{D}$ Modelling and Information System, Remote Sensing and GIS Research Group, Bandung Institute of Technology, Indonesia - \\ deni@gd.itb.ac.id, kamal.fauzan55@gmail.com \\ ${ }^{2}$ Université de Strasbourg, INSA Strasbourg, CNRS, ICube Laboratory UMR 7357, Photogrammetry and Geomatics Group, 67000 \\ Strasbourg, France - arnadi.murtiyoso@ insa-strasbourg.fr \\ ${ }^{3}$ Geodesy Research Group, Bandung Institute of Technology, Indonesia \\ igumilar@gd.itb.ac.id, teguh.purnama@yahoo.com
}

\section{Commission II}

KEY WORDS: close-range photogrammetry, deformation, monitoring, metrology, Gas Insulated Line (GIL)

\begin{abstract}
:
Close-Range Photogrammetry (CRP) technology advanced rapidly along with the development of camera sensors. CRP has many advantages over other methods in terms of technical data acquisition, product quality, and cost. Because of these advantages, the CRP method can be used in various applications. In this study, the CRP method is used to monitor the deformation of the SF6 Gas Insulated Line (GIL) object between two substations of the Indonesian National Electricity Service in Kuningan Barat, South Jakarta. Planning was carried out with a simulation using 3D field data obtained from reconnaissance process. During the survey, photo data was collected using a smartphone and processed to form a 3D model. The simulation produced a configuration of control points, check points, and camera stations that have the best Strength of Figure ( $\mathrm{SoF}$ ) values. In the planning process, camera pre-calibration is carried out to get the best camera orientation parameter values from several experiments. The planning results are used in the next stage, namely field data acquisition and data processing. The data acquisition process was carried out for two sessions. This is done to see the changes in coordinates that occur between these sessions. Data processing was carried out by following the classical photogrammetric stages. The results obtained from this study are the average accuracy produced by Close-Range Photogrammetry method for measuring deformation which is below a tolerance of $3 \mathrm{~mm}$. With this method, deformation measurements can be carried out quickly, accurately, and at a relatively lower cost than other observation methods.
\end{abstract}

\section{INTRODUCTION}

Deformation monitoring is an essential part of natural disaster mitigation efforts to reduce the impact of such events. Deformation is a change of the dimensions and, in some cases, the shape of a body due to an applied external force (Ratner, 2003). Deformation analysis is carried out by geometric analysis and physical interpretation of the deformed object. Geometric analysis can be done by quantifying the amount of deformation that occurs by determining the coordinate shift vector's magnitude. The calculation of the geometric deformation in some cases requires observations that yield data down to the millimetre fraction. This must be supported by tools, technology, and methods, requiring data resolution of up to the fraction of millimetre and submillimetre in some instances.

Deformation observations have been carried out by several methods, such as terrestrial, extra-terrestrial, and remote sensing methods. Each object was observed with different methods and tools according to their needs. For example, observing the deformation of construction objects such as tunnel and dams is done using the terrestrial method with the Terrestrial Laser Scanner (TLS) (Xie and Lu, 2017) and extra-terrestrial method with the Global Navigation Satellite System (GNSS) (Xiao et al., 2019). Deformation observations using remote sensing technology are carried out on relatively large objects, such as ground deformation in earthquake cases (Ganas et al., 2020).

In this research, the object required to be observed is SF6 Gas Insulated Line (GIL) between two substations of the Indonesian National Electricity Service in Kuningan Barat, South Jakarta.
GIL is a transmission system that can be used as an alternative to conventional cables when overhead lines are not a practical solution (Koch, 2019). GIL has a role as a link between the electric power generated from the generator and the transmission line (Bimantara et al., 2010). Construction activities around the area are a major factor causing deformation in GIL. The deformation of GIL will affect the performance and safety of the operation. A system must be implemented to detect deformations in GIL to avoid potential losses. According to the Indonesian National Electricity Service, the method must be able to detect the deformation for at least $3 \mathrm{~mm}$ and be carried out periodically.

An efficient alternative method is needed to simplify and speed up deformation monitoring and measurement to overcome these problems. The method proposed is the Close-Range Photogrammetry (CRP) method using a digital non-metric camera. This proposal was taken considering that the CRP technique has advantages, especially if the object measured has relatively small dimensions (Galantuci et al., 2016). Besides, advances of digital camera technology has developed very rapidly in recent years. With a very varied resolution capability and high camera stability, CRP has been proved to be able to carry out deformation surveys (Peterman, 2010). Another advantage is that digital camera is cheaper than other surveying tools such as total station, GNSS, and Terrestrial Laser Scanner (TLS) (Franceschini et al., 2014).

In this paper, we propose CRP method to be used as a deformation measurement solution for small objects with high accuracy and low cost, specifically in the case of SF6 Gas Insulated Line (GIL) objects. 


\section{PROPOSED METHODOLOGY AND DATA}

\subsection{Overview}

This research aims to compute the object's coordinates as accurately as possible using the CRP method. Figure 1 shows the research procedure to observe the SF6 Gas Insulated Line's deformation. The study is divided into three main parts: planning, data acquisition, and data processing.

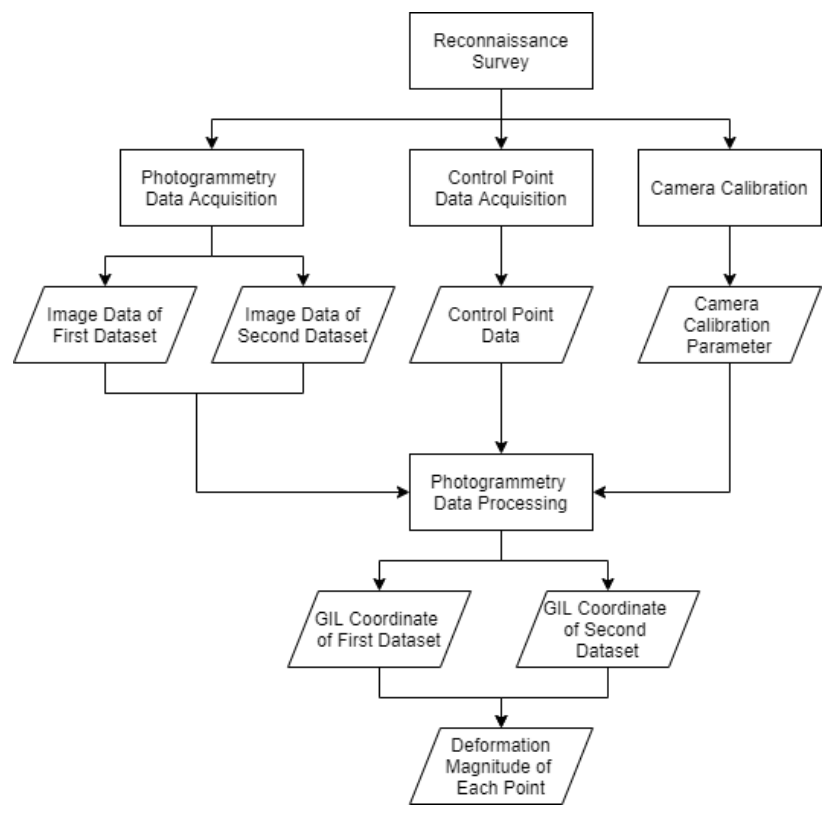

Figure 1. Schema of the proposed method

The planning stages includes reconnaissance survey, simulation, and camera calibration. Job planning is carried out to make field data acquisition run effectively, as optimal results can be obtained by doing optimal planning as well. Field data acquisition was carried out by following the procedures prepared in the job planning step. Data processing was carried out to obtain deformation on the test object by comparing two photogrammetric data sets at different times. Data processing was performed using the Australis 6 software by following classical photogrammetry processing steps, which included resection, intersection, and bundle adjustment. A detailed description of the steps will be explained in the following sections.

\subsection{Reconnaissance Survey and Planning}

The reconnaissance survey involves the initial activity to conduct field recognition. One of the things performed during the reconnaissance survey is a preliminary study of the geometry of the object to be observed. The observed GIL has a length of 38 $\mathrm{m}$ which is placed on $3 \mathrm{~m}$ supporting pillars. The diameter of the GIL in question is $70 \mathrm{~cm}$.

During the reconnaissance survey, some photos were taken using a smartphone camera to form a rough $3 \mathrm{D}$ photogrammetric model of the field. The smartphone used is the Oppo A1k which has a camera specification of $8 \mathrm{MP}$ and a focal length of $27 \mathrm{~mm}$. This is done to facilitate the planning process since planning on 3D model can be more effective. In principle, the CRP method requires images that are taken from various directions and positions. Besides that, there must be areas where one photo overlaps with another so that the photogrammetric process can be carried out and a 3D model can be formed. The number of photos taken from the field is 172 photos. The examples of photos taken in the field can be seen in Figure 2.
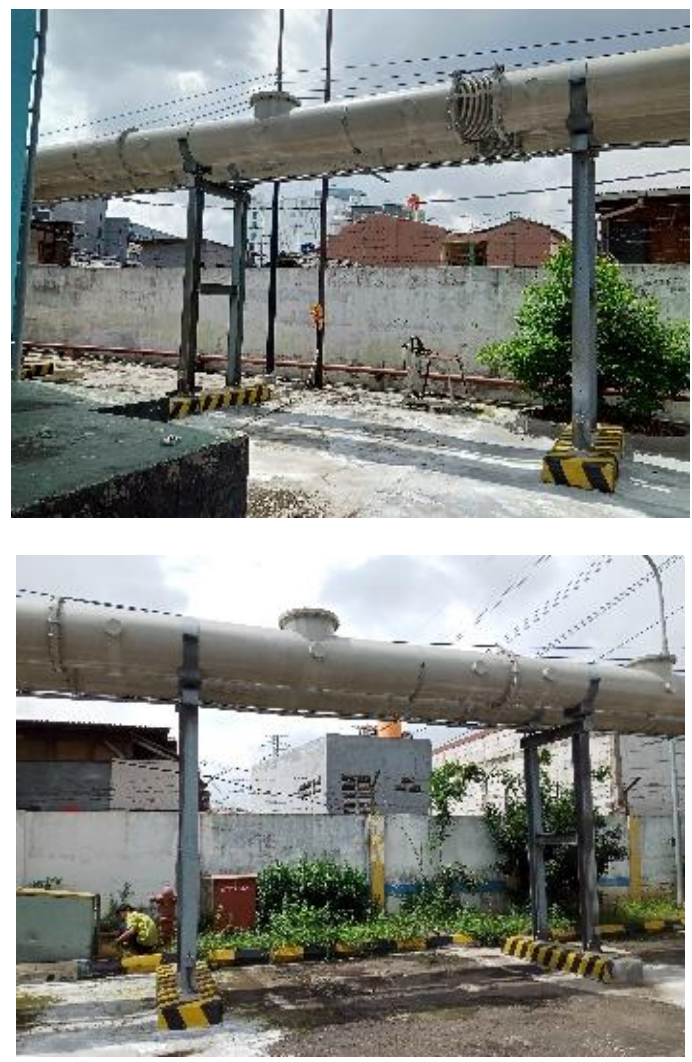

Figure 2. Photos taken in reconnaissance survey to build 3D model of site

The photos that were taken are then processed to produce a dense point cloud that will be used as a source for making 3D models. The photogrammetric software used in this case is Agisoft Metashape. 3D modelling was done using Cloud Compare and ArchiCAD. The 3D model of the site can be seen in Figure 3.
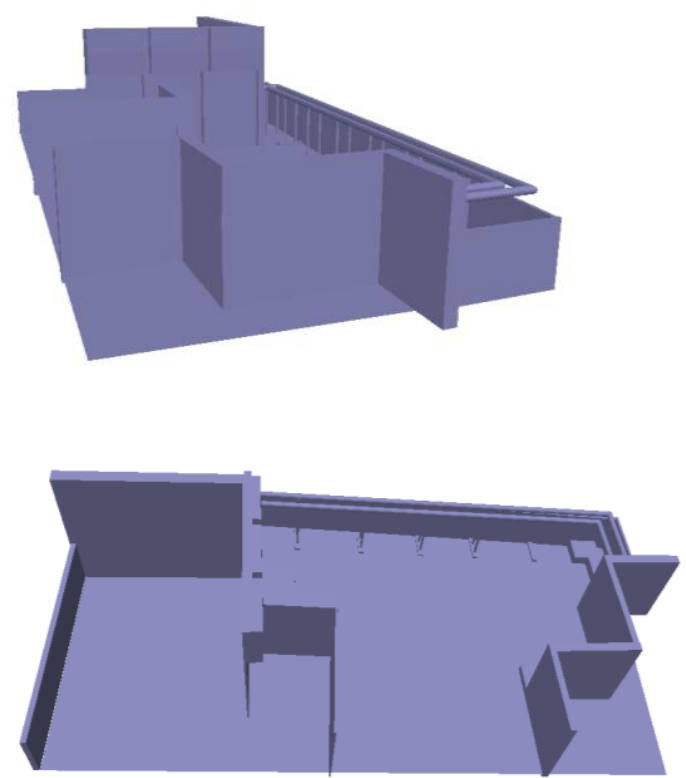

Figure 3. 3D Model of the GIL site 
The modelling results are used for simulating the target points and camera station points. The simulation process resulted in sixty target points and eight camera station points. The results of the planning can be used to calculate the strength of the photogrammetric network. The simulated target points and camera station points can be seen in Figure 4. The target points consist of both control points and check points. Control points are placed on the supporting pillars because it is assumed to be more stable and less likely to be deformed. Check points are placed on the pipes between the supporting piles. The deformation of the GIL can be monitored with these check points.

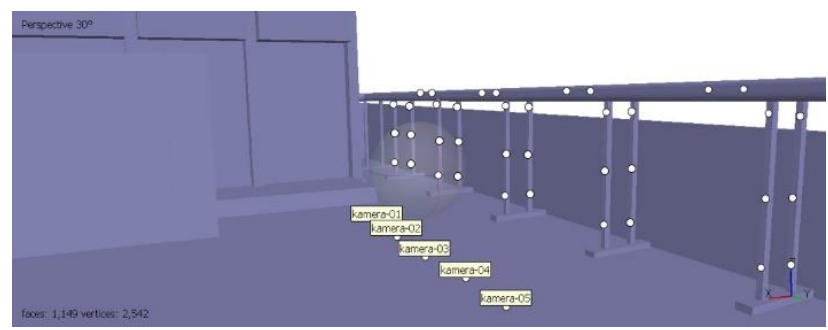

(a)

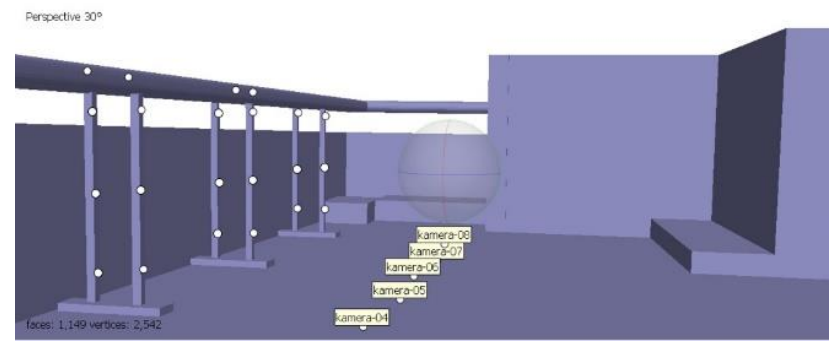

(b)

Figure 4. The location of target points and camera station points as generated from the simulation process from (a) right side and (b) left side

\subsection{Camera Calibration}

The camera used to carry out the deformation survey is a Nikon D5200 DSLR camera. The camera is a non-metric camera that is not explicitly used as a measurement tool, so it is necessary to calibrate it. According to Griffiths and Burningham (2018), photogrammetric processing with the pre-calibration method produces a more accurate product than the self-calibration method. To get accurate results in this study, the calibration method used is pre-calibration.

Camera calibration is carried out at two different places, namely indoors in the form of target points and outdoors in the form of patterns on walls. The target used to perform camera calibration can be seen in Figure 5.

Photo calibration data were collected in several directions with different orientations. Also, the acquisition was carried out at different distances. This is done to get a precise and consistent camera calibration value. Photogrammetric data processing was carried out on Agisoft Metashape and Australis software. The camera configuration for indoor camera calibration and outdoor camera calibration can be seen in Figure 6 .

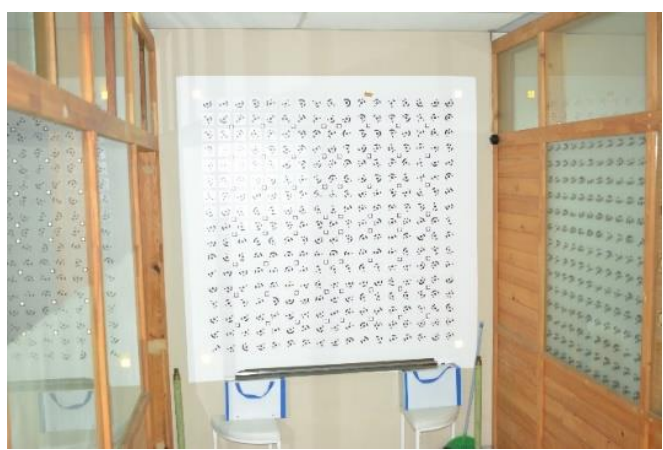

(a)

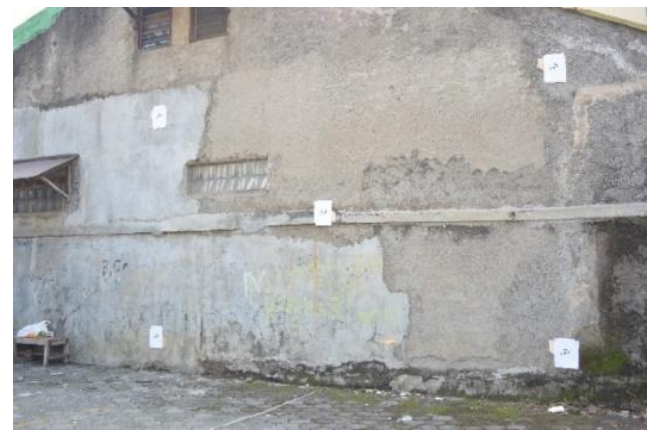

(b)

Figure 5. (a) Indoor camera calibration target and (b) outdoor camera calibration target

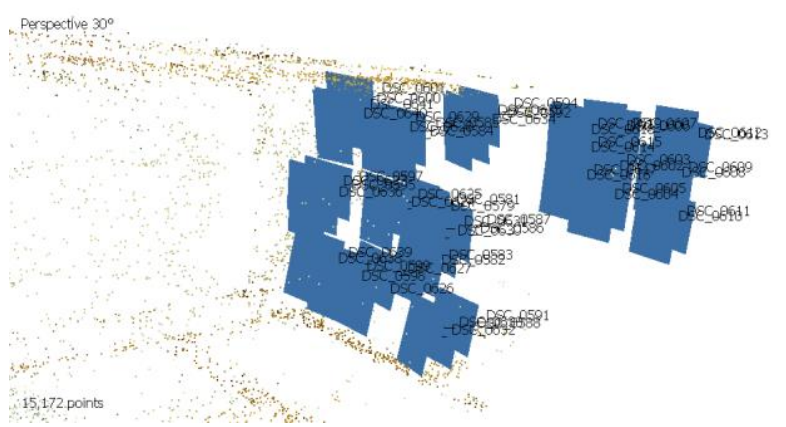

(a)

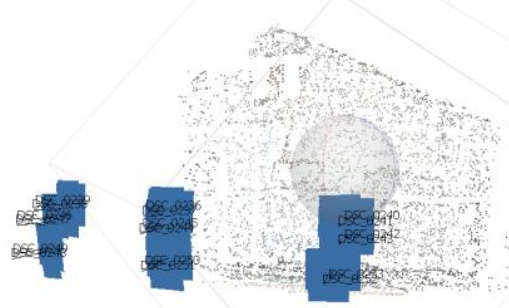

(b)

Figure 6. Camera configuration for (a) indoor camera calibration and (b) outdoor camera calibration

Camera calibration parameters between indoor and outdoor observations are compared, and the best results are used for photogrammetric processing for deformation observations at a later stage. The best results can be seen from the standard deviation values generated from each camera parameter. 


\subsection{Data Acquisition}

Field data acquisition consists of two parts: acquisition of target point coordinate data using Topcon MS05 Robotic Total Station and photogrammetric data acquisition using Nikon D5200 DSLR camera.

\subsubsection{Target Points Data Acquisition}

Acquisition of target points coordinate data is performed using Topcon MS05 Robotic Total Station (RTS). The theoretical angular accuracy of this tool is 0.5 ". Target measurement is carried out at a distance of $10-15 \mathrm{~m}$ so that the accuracy of the point obtained meets the tolerance threshold. The accuracy value that must be achieved in this observation is $1-2 \mathrm{~mm}$ to meet the tolerance for deformation that occurs around 3-5 mm.

The target used in this study is a retro-reflective target that has a diameter of $1.27 \mathrm{~cm}$. Retro-reflective targets are used because they have good contrast. Retro-reflective target can be detected automatically by the RTS. Besides, the target detection during the processing process can be done automatically to reduce operator error. An example of the target can be seen in Figure 7.

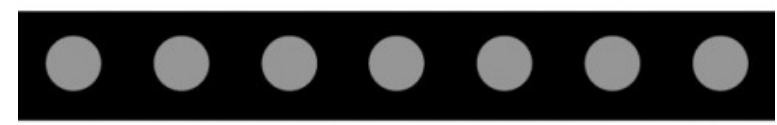

Figure 7. Retro-reflective targets used in the study.

There are 54 target points on the pillars as control points and 15 target points on the pipe as check points. The example of check point and control point can be seen in Figure 8.

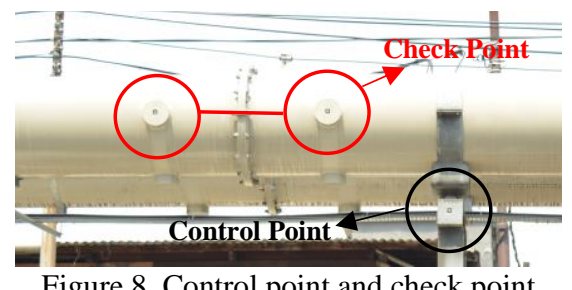

Figure 8. Control point and check point

The polar method in the local coordinate system is used in the measurement. The RTS stands seven times, with each station points having no absolute coordinate point, so that we obtain seven sets of target point coordinates in 7 different coordinate systems. The transformation is done by making coordinates on the first measurement as a reference, and other measurements are transformed based on the coordinates of the first measurement. In this case, the traverse method using backsight is not used to avoid errors in the control points' coordinates and errors when centering the tool. Coordinate transformation is carried out to make the coordinates of all points in the same coordinate system.

\subsubsection{Photogrammetry Data Acquisition}

Photogrammetry data acquisition is performed using a Nikon D5200 DSLR camera. The focal length of the camera is fixed at $24 \mathrm{~mm}$. The focal length is used to retrieve data as far as $7 \mathrm{~m}$ from the object and produce a theoretical Ground Sampling Distance (GSD) of $1 \mathrm{~mm}$. The camera was used to take images from eight camera station points. Each camera stand took a total of six photos. The six photos include portrait straight shot, landscape straight shot, portrait left-oblique shot, landscape leftoblique shot, portrait right-oblique shot, and landscape rightoblique shot. Illustrations of the data acquisition method in the field can be seen in Figure 9. The minimum number of photo data used in the deformation survey is 48 photos.

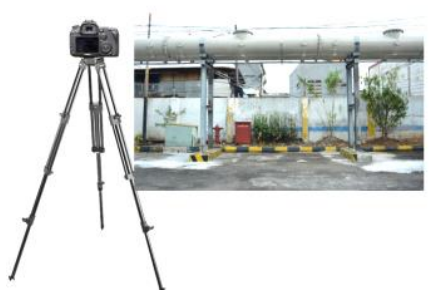

(a)

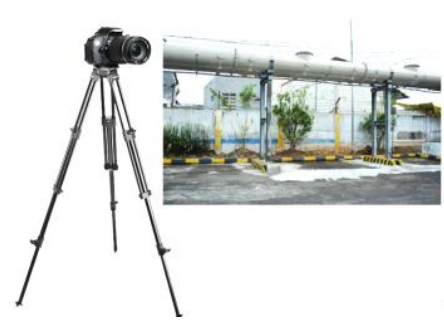

(c)

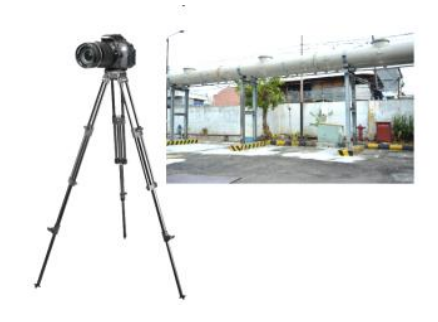

(e)

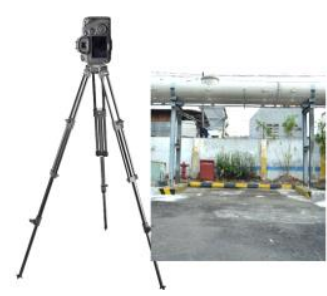

(b)

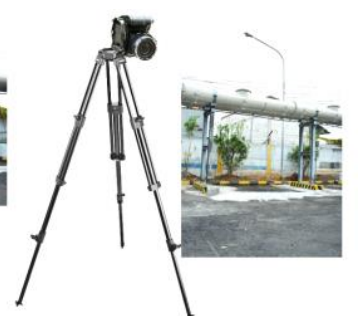

(d)

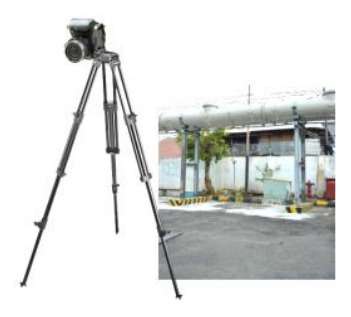

(f)
Figure 9. Taking photos with (a) portrait straight shot, (b) landscape straight shot, (c) right-oblique portrait shot, (d) rightoblique landscape shot, (e) left-oblique portrait shot, and (f) right-oblique landscape shot

From the measurement, it is recommended that data collection be carried out in the morning or evening when the sun is less bright. Images that are too light will make it difficult to mark. The photo was taken only for two pillars. One pile will cause the photo not to process correctly; more than two piles will cause many dots too small to be tagged. As validation, the pictures were taken at two different times. One dataset is taken in the morning, and the other dataset is taken in the afternoon.

\subsection{Data Processing}

Photogrammetry data processing was carried out in Australis 6 software. The Australis photogrammetry software is designed to take highly automated off-line measurements of a network of monoscopic/convergent digital images, using either a digital camera or a scanned film image. This software is beneficial for metrology applications with a very high precision level, either using a metric camera or a moderate to low accuracy. (Photometrix, 2004).

Processing follows the photogrammetric steps from Australis 6 including resection, bundle adjustment, and intersection. The coordinates of the target points were obtained after all processing on Australis 6 was carried out. 


\subsubsection{Space Resection}

Space resection is a photogrammetric process to determine the position and spatial orientation of a photo based on photogrammetric measurements from the ground control points seen in the photo (Moffit and Mikhail, 1980). Space resection in photogrammetry has the same analogy with space resection in survey. Based on established basic definitions, the spatial resection of a photograph can be used to express position and orientation parameters or just positional parameters. Therefore, the resection chamber can have three parameters $(X c, Y c, Z c)$, six parameters (Xc, Yc, Zc, $\omega, \varphi, \kappa)$, or more (Masry, 1979). An illustration of the space resection process can be seen in Figure 10 .

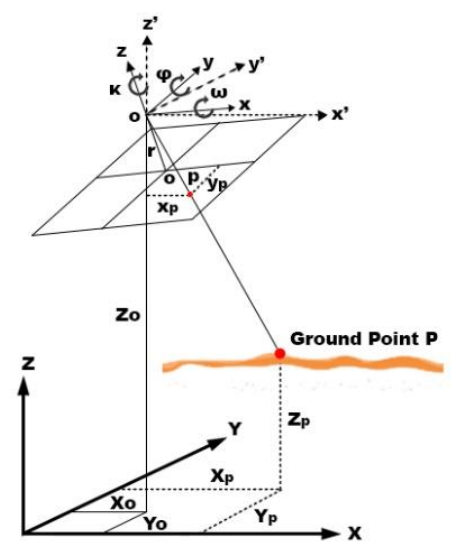

Figure 10. Illustration of space resection in photogrammetry (Mikhail et al., 2001)

In this case, resection is carried out to obtain the external orientation of the camera. Marking of points on photos is done first to get the image coordinate value of each point. The marking of points is carried out by a semi-automatic method to reduce errors. An example of marking the points on a photo can be seen in Figure 11. The resection process is carried out using all target points. The resection process will produce external parameters of the cameras. The position of the resected camera can be seen in Figure 12.

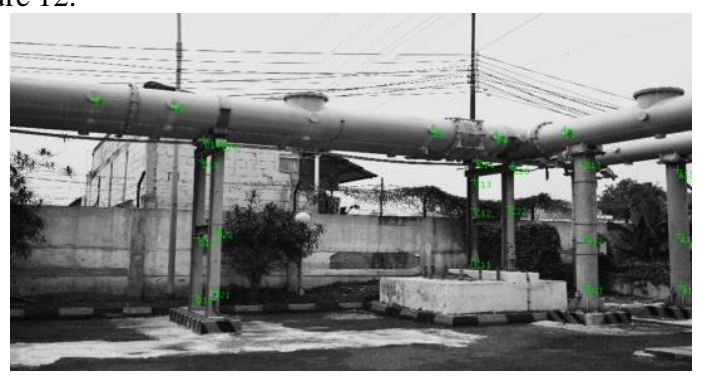

Figure 11. Target points marking in Australis 6

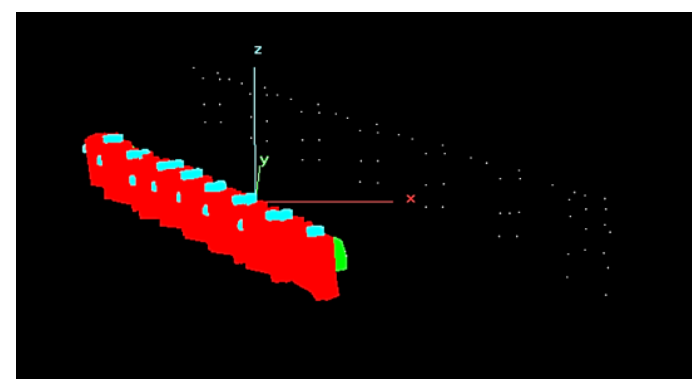

Figure 12. Camera configuration resulted from resection process

\subsubsection{Bundle Adjustment}

Bundle adjustments is the problem of refining a visual reconstruction to produce jointly optimal 3D structure and viewing parameter (camera pose or calibration) estimates (Triggs, 2000). Bundle adjustments are perfomed to obtain camera position or out-of-camera orientation parameters accurately. The photogrammetric processing quality is determined by the results of the bundle adjustment that is carried out.

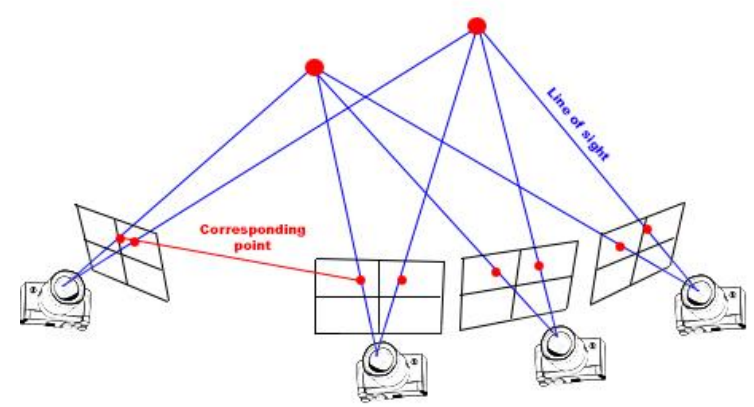

Figure 13. Illustration of Bundle Adjustment in Photogrammetry (Doumit, 2019)

\subsubsection{Intersection}

To get an object's position in the real world requires the same line of the object from other photos (Leitch, 2010). The two lines will intersect on the same object in the real world. This intersection is called a spatial intersection (Atkinson, 1996). The principle of determining the positions of the intersections of these rays is known as the spatial intersection. An illustration of the space intersection process can be seen in Figure 14.

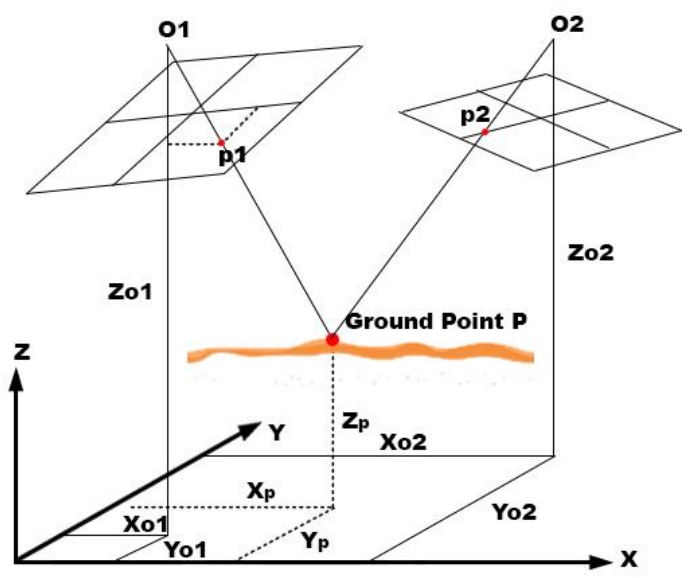

Figure 14. Illustration of space intersection in photogrammetry (Mikhail et al., 2001)

The intersection is used to get the final coordinates of the target point on the SF6 GIL. The coordinates of the intersection results are used as a reference to determine the amount of pipe deformation at that time. 


\section{RESULTS AND DISCUSSION}

\subsection{Camera Calibration Results}

The previous section explained that the camera calibration value obtained from the pre-calibration process affects the observation results' accuracy and geometric quality. In this case, camera calibration is carried out to obtain various camera parameter values.

Table 1 and Table 2 show the parameters of the camera's inner orientation using two cases, namely indoor and outdoor observations.

\begin{tabular}{|c|c|c|}
\hline Parameter & Value & $\begin{array}{c}\text { Standard } \\
\text { Deviation }\end{array}$ \\
\hline C & 24.2828 & $0.0004(\mathrm{~mm})$ \\
\hline Xp & 0.0473 & $0.0004(\mathrm{~mm})$ \\
\hline Yp & 0.0199 & $0.0003(\mathrm{~mm})$ \\
\hline K1 & $1.70097 \mathrm{e}-004$ & $1.25378 \mathrm{e}-007$ \\
\hline K2 & $-2.99064 \mathrm{e}-007$ & $1.70664 \mathrm{e}-009$ \\
\hline K3 & $1.15136 \mathrm{e}-10$ & $6.89963 \mathrm{e}-012$ \\
\hline P1 & $-1.90103 \mathrm{e}-005$ & $1.11859 \mathrm{e}-007$ \\
\hline P2 & $1.85122 \mathrm{e}-006$ & $8.64572 \mathrm{e}-008$ \\
\hline B1 & $-4.93488 \mathrm{e}-005$ & $1.48439 \mathrm{e}-006$ \\
\hline B2 & $3.63967 \mathrm{e}-006$ & $1.55778 \mathrm{e}-006$ \\
\hline
\end{tabular}

Table 1. Camera parameter resulted from indoor camera calibration

\begin{tabular}{|c|c|c|}
\hline Variable & Value & $\begin{array}{c}\text { Standard } \\
\text { Deviation }\end{array}$ \\
\hline C & 24.9025 & $0.0005(\mathrm{~mm})$ \\
\hline Xp & 0.0327 & $0.0003(\mathrm{~mm})$ \\
\hline Yp & 0.0170 & $0.0003(\mathrm{~mm})$ \\
\hline K1 & $1.58143 \mathrm{e}-004$ & $2.62362 \mathrm{e}-007$ \\
\hline K2 & $-2.38032 \mathrm{e}-007$ & $2.53367 \mathrm{e}-009$ \\
\hline K3 & $7.18729 \mathrm{e}-012$ & $8.08693 \mathrm{e}-012$ \\
\hline P1 & $-1.09796 \mathrm{e}-005$ & $1.16404 \mathrm{e}-007$ \\
\hline P2 & $-1.64992 \mathrm{e}-006$ & $1.07544 \mathrm{e}-007$ \\
\hline B1 & $0.00000 \mathrm{e}+000$ & $1.15065 \mathrm{e}-008$ \\
\hline B2 & $0.00000 \mathrm{e}+000$ & $4.76532 \mathrm{e}-009$ \\
\hline
\end{tabular}

Table 2. Camera parameter resulted from outdoor camera calibration

The difference of focal length parameter (c) is significant between indoor and outdoor calibration. The focal length parameter (c) is the most crucial in photogrammetric data processing.

The quality of the camera orientation parameter value used can be seen from the resulting standard deviation value. The value of the camera orientation parameter produced by indoor is better than the result outdoor. The indoor camera calibration result was therefore used in the photogrammetric processing stage.

\subsection{Photogrammetry Processing Results}

Photogrammetric data processing is carried out through several classical photography stages such as resection, bundle adjustment, and intersection. The number of photos used was 62 photos in session 1 and 48 photos in session 2 . The data generated by the resection process is the external orientation parameter data from the camera, along with the standard deviation of camera position. The average standard deviation value from each camera is $2.05 \mathrm{~mm}$ for session 1 and $1.7 \mathrm{~mm}$ for session 2 . The camera position can be seen in Figure 15.

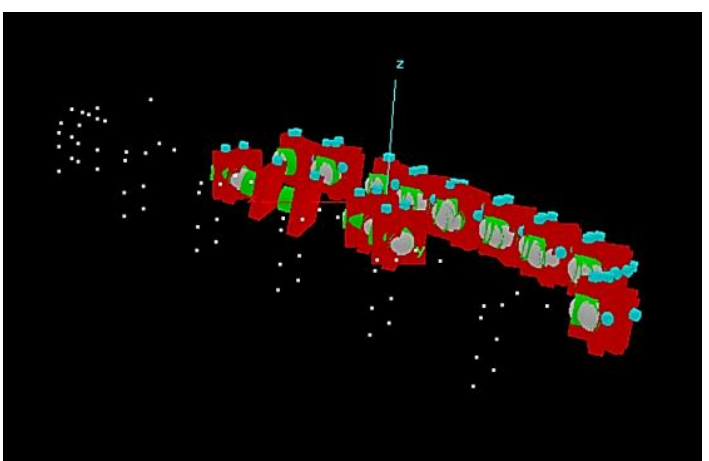

(a)

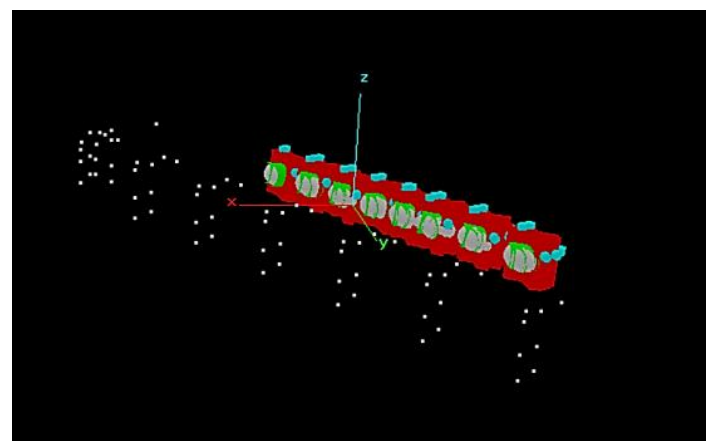

(b)

Figure 15. The position of the camera resulting from the resection process in (a) session 1 and (b) session 2

The next step is to do the bundle adjustment process. The data generated from the bundle adjustment process are the parameter values of the camera's external parameter that has been computed and the target points' coordinates. Furthermore, there is an RMS value in the bundle adjustment process and a sigma naught value. The resulting sigma naught value is $1.486 \mu \mathrm{m}$ for session 1 and $1.391 \mu \mathrm{m}$ for session 2. Sigma Naught is the mean square error (MSQE) of the observation resulting from the observations' adjustment. Sigma naught is computed as a quality indicator (Zeitler et al., 2002).

\begin{tabular}{|c|c|c|c|c|c|c|c|}
\hline \multicolumn{2}{|c|}{ Total Residuals (RMS) } & \multirow{2}{*}{ Sigma0 } \\
$\left(\begin{array}{c}\mathbf{X} \\
(\mathbf{m m})\end{array}\right.$ & $\begin{array}{c}\mathbf{Y} \\
(\mathbf{m m})\end{array}$ & $\begin{array}{c}\mathbf{X y} \\
(\mathbf{m m})\end{array}$ & DoF & $\begin{array}{c}\text { Obser- } \\
\text { vation }\end{array}$ & $\begin{array}{c}\text { Para- } \\
\text { meter }\end{array}$ & $\begin{array}{c}\text { Cons- } \\
\text { trains }\end{array}$ \\
\hline 0.52 & 0.54 & 0.53 & 1.486 & 408 & 786 & 436 & 58 \\
\hline
\end{tabular}

Table 3. Bundle adjustment report from session 1 processing

\begin{tabular}{|c|c|c|c|c|c|c|c|}
\hline \multicolumn{2}{|c|}{ Total Residuals (RMS) } & \multirow{2}{*}{ Sigma0 } & DoF & $\begin{array}{c}\text { Obser- } \\
\text { vation }\end{array}$ & $\begin{array}{c}\text { Para- } \\
\text { meter }\end{array}$ & $\begin{array}{c}\text { Cons- } \\
\text { trains }\end{array}$ \\
\cline { 1 - 5 } $\mathbf{X}$ & $\begin{array}{c}\mathbf{Y} \\
(\mathbf{m m})\end{array}$ & $\begin{array}{c}\mathbf{X y} \\
(\mathbf{m m})\end{array}$ & & & & & \\
\hline 0.50 & 0.56 & 0.53 & 1.391 & 528 & 888 & 415 & 55 \\
\hline
\end{tabular}

Table 4. Bundle adjustment report from session 2 processing

The result of photogrammetric processing is the coordinates of each check points on the SF6 GIL. There are 15 check points on the SF6 GIL that are evenly distributed. The coordinates of the check points in session 1 and session 2 with the uncertainty value can be seen in Table 5 and Table 6 . 


\begin{tabular}{|c|c|c|c|c|c|c|}
\hline ICP & $\begin{array}{c}\mathbf{X} \\
(\mathbf{m m})\end{array}$ & $\begin{array}{c}\mathbf{Y} \\
(\mathbf{m m})\end{array}$ & $\begin{array}{c}\mathbf{Z} \\
(\mathbf{m m})\end{array}$ & $\begin{array}{c}\text { Error } \\
\mathbf{X}\end{array}$ & $\begin{array}{c}\text { Error } \\
\mathbf{Y}\end{array}$ & $\begin{array}{c}\text { Error } \\
\mathbf{Z}\end{array}$ \\
\hline P1 & 9727.1 & -8419.3 & 2131.6 & 0.02 & 0.03 & 0.02 \\
\hline P2 & 12217.9 & -6756.4 & 2128.4 & 0.01 & 0.01 & 0.02 \\
\hline P3 & 12909.2 & -6172.5 & 2124.9 & 0.02 & 0.01 & 0.02 \\
\hline P4 & 12612.0 & -5724.3 & 2122.2 & 0.01 & 0.00 & 0.01 \\
\hline P5 & 11938.9 & -4715.5 & 2120.0 & 0.02 & 0.01 & 0.01 \\
\hline P6 & 9714.7 & -1402.9 & 2116.3 & 0.01 & 0.01 & 0.01 \\
\hline P7 & 9160.0 & -574.9 & 2115.2 & 0.01 & 0.01 & 0.01 \\
\hline P8 & 6934.3 & 2747.1 & 2112.4 & 0.17 & 0.15 & 0.14 \\
\hline P9 & 6384.9 & 3574.1 & 2108.4 & 0.17 & 0.14 & 0.14 \\
\hline P10 & 4163.1 & 6918.7 & 2112.5 & 0.16 & 0.16 & 0.14 \\
\hline P11 & 3606.5 & 7757.9 & 2110.3 & 0.16 & 0.17 & 0.15 \\
\hline P12 & 1387.9 & 11096.2 & 2082.9 & 0.01 & 0.01 & 0.01 \\
\hline P13 & 719.4 & 12098.4 & 2076.6 & 0.01 & 0.01 & 0.01 \\
\hline P14 & -1222.2 & 15010.7 & 2058.8 & 0.00 & 0.01 & 0.01 \\
\hline P15 & -1949.1 & 16100.0 & 2057.1 & 0.01 & 0.01 & 0.01 \\
\hline
\end{tabular}

Table 5. Results of SF6 GIL coordinates in session 1

\begin{tabular}{|c|c|c|c|c|c|c|}
\hline ICP & $\begin{array}{c}\mathbf{X} \\
(\mathbf{m m})\end{array}$ & $\begin{array}{c}\mathbf{Y} \\
(\mathbf{m m})\end{array}$ & $\begin{array}{c}\mathbf{Z} \\
(\mathbf{m m})\end{array}$ & $\begin{array}{c}\text { Error } \\
\mathbf{X}\end{array}$ & $\begin{array}{c}\text { Error } \\
\mathbf{Y}\end{array}$ & $\begin{array}{c}\text { Error } \\
\mathbf{Z}\end{array}$ \\
\hline P2 & 12215.4 & -6755.9 & 2127.2 & 0.01 & 0.01 & 0.01 \\
\hline P3 & 12913.1 & -6173.1 & 2125.7 & 0.02 & 0.01 & 0.05 \\
\hline P4 & 12610.8 & -5724.4 & 2122.2 & 0.01 & 0.00 & 0.00 \\
\hline P5 & 11936.9 & -4715.6 & 2119.7 & 0.01 & 0.01 & 0.01 \\
\hline P6 & 9715.2 & -1402.5 & 2116.5 & 0.01 & 0.01 & 0.01 \\
\hline P7 & 9160.8 & -574.4 & 2115.6 & 0.01 & 0.01 & 0.01 \\
\hline P8 & 6935.5 & 2751.8 & 2114.2 & 0.16 & 0.14 & 0.13 \\
\hline P9 & 6385.2 & 3578.6 & 2109.2 & 0.15 & 0.14 & 0.13 \\
\hline P10 & 4162.8 & 6921.6 & 2112.3 & 0.07 & 0.07 & 0.06 \\
\hline P11 & 3602.9 & 7757.6 & 2108.8 & 0.06 & 0.07 & 0.06 \\
\hline P12 & 1387.5 & 11095.8 & 2082.6 & 0.01 & 0.01 & 0.01 \\
\hline P13 & 720.3 & 12099.4 & 2076.8 & 0.01 & 0.01 & 0.01 \\
\hline P14 & -1222.3 & 15010.4 & 2058.5 & 0.01 & 0.01 & 0.01 \\
\hline P15 & -1948.4 & 16101.1 & 2057.4 & 0.01 & 0.02 & 0.02 \\
\hline
\end{tabular}

Table 6. Results of SF6 GIL coordinates in session 2

In session 1, all check points can be measured, while in session 2, point P1 cannot be measured, and the coordinates cannot be known. This is because point $\mathrm{P} 1$ is at the end of the pipe, and many points on the photo cannot be detected at the time of pinching, which results in a lack of resection line at point $\mathrm{P} 1$.

The difference in coordinates between measurements is assumed to be the deformation between the two measurement epochs. The method of close-range photogrammetry should be able to detect changes below $3 \mathrm{~mm}$. Ideally, the difference between the coordinates of phase 1 and phase 2 processing is below $3 \mathrm{~mm}$ for the $\mathrm{X}, \mathrm{Y}$, and $\mathrm{Z}$ components. The results of the difference in coordinates between phase 1 and phase 2 can be seen in Table 7 .

\begin{tabular}{|c|c|c|c|}
\hline \multirow{2}{*}{ ICP } & \multicolumn{3}{|c|}{ Difference } \\
\cline { 2 - 4 } & $\mathbf{X}(\mathbf{m m})$ & $\mathbf{Y}(\mathbf{m m})$ & $\mathbf{Z}(\mathbf{m m})$ \\
\hline P2 & 2.4 & -0.5 & 1.3 \\
\hline P3 & -3.9 & 0.7 & -0.8 \\
\hline P4 & 1.2 & 0.1 & 0.0 \\
\hline P5 & 2.1 & 0.1 & 0.3 \\
\hline P6 & -0.5 & -0.3 & -0.2 \\
\hline P7 & -0.8 & -0.6 & -0.4 \\
\hline P8 & -1.2 & -4.8 & -1.8 \\
\hline P9 & -0.4 & -4.5 & -0.8 \\
\hline P10 & 0.3 & -2.9 & 0.2 \\
\hline P11 & 3.6 & 0.3 & 1.5 \\
\hline P12 & 0.4 & 0.4 & 0.3 \\
\hline P13 & -0.8 & -1.0 & -0.1 \\
\hline P14 & 0.1 & 0.3 & 0.2 \\
\hline P15 & -0.7 & -1.2 & -0.3 \\
\hline
\end{tabular}

Table 7. The difference between the results of the measurement coordinates of session 1 and session 2

The processing results show that the difference in coordinates generated by session 1 and session 2 on average is below $3 \mathrm{~mm}$ with $1.76 \mathrm{~mm}$ deviation standard for $\mathrm{X}$ and $\mathrm{Y}$ components and $0.8 \mathrm{~mm}$ deviation standard for $\mathrm{Z}$ component. Only four shift components have a value of more than $3 \mathrm{~mm}$, namely the $X$ component of point $\mathrm{P} 3$, component $\mathrm{Y}$ point $\mathrm{P} 4$, component $\mathrm{Y}$ point $\mathrm{P} 3$, and component $\mathrm{X}$ point $\mathrm{P} 11$. For point $\mathrm{P} 2$, this is because the point is at the end of the pipe so that fewer photos are taken. Points P8, P9, and P11 in measurement session 1 have higher error values than other points, causing coordinate differences that exceed tolerance. This is because the camera configuration in that area is not ideal, or in other words, it has a low value of the geometric strength coefficient. This can be anticipated by increasing the number of camera stations facing that point.

\section{CONCLUSIONS}

This study attempts to demonstrate the CRP method to measure the deformation of the SF6 GIL pipe. The stages of this research generally follow classical photogrammetric processing steps but require additional steps so that the resulting accuracy is very high and meets the predetermined $3 \mathrm{~mm}$ accuracy tolerance.

The initial process and also the camera calibration process is quite crucial. Calibration is done indoors and outdoors. These results are compared, and the camera calibration for indoors is better than the results from outdoor calibration.

The results obtained from this study are the accuracy produced by the photogrammetric close-range method for deformation measurement, which yielded an average value below a tolerance of $3 \mathrm{~mm}$. The accuracy of the measurements can be increased by adjusting the strength of the geometric network of the camera to be as good as possible. With this method, deformation measurements can be carried out quickly, accurately, and at a relatively lower cost than other observation methods. 


\section{REFERENCES}

Atkinson, 1996. Close Range Photogrametry and Machine Vision. Scotland, UK: Whittles Publishing.

Bimantara, A., Prabowo, G., Rofiq, A., 2010. Studi Tentang Sistem Interlocking pada Gas Insulated Switchgear $500 \mathrm{kV}$ di PLTU Paiton Unit 7 dan 8. Undergraduate Thesis of Electrical Industry, ITS.

Doumit, J., 2019. From Drones to Geospatial Analysis. Kuban State University.

Franceschini, F., Galetto, M., Maisano, D., Mastrogiacomo, L., 2014. Large-scale dimensional metrology (LSDM): from tapes and theodolites to multi-sensor systems. International Journal of Precision Engineering and Manufacturing, 15(8), 1739-1758. doi:10.1007/s12541-014-0527-2

Galantucci, L.M., Pesce, M., Lavecchia, F., 2016. A powerful scanning methodology for 3D measurements of small parts with complex surfaces and sub millimeter-sized features, based on close range photogrammetry. Precision Engineering, 43, 211219. doi:10.1016/j.precisioneng.2015.07.010

Ganas, A., Elias, P., Briole, P., Cannavo, F., Valkaniotis, S., Tsironi, V., Partheniou, E. I., 2020. Ground Deformation and Seismic Fault Model of the M6.4 Durres (Albania) Nov. 26, 2019 Earthquake, Based on GNSS/INSAR Observations. Geosciences, 10(6), 210. doi:10.3390/geosciences 10060210

Griffiths, D., \& Burningham, H., 2018. Comparison of pre- and self-calibrated camera calibration models for UAS-derived nadir imagery for a SfM application. Progress in Physical Geography: Earth and Environment. doi:10.1177/0309133318788964

Koch, H., 2019. Gas Insulated Lines (GIL). In: Krieg T., Finn J. (eds) Substations. CIGRE Green Books. Springer, Cham. doi:10.1007/978-3-319-49574-3_27.

Leitch, K. R., 2010. Close Range Photogrammetric Measurement of Bridge Deformation. New Mexico: Lambert Academic Publishers.

Masry, S.E., 1977. Basics of Instrumental and Analytical Photogrammetry. Lecture Notes No. 33, Department of Surveying Engineering, University of New Brunswick, Fredericton, N.B., Canada.

Mikhail, E. M., Bethel, J. S., dan McGlone, J. C., 2001. Introduction to Modern Photogrammetry, John Wiley and Sons Inc., NewYork, USA

Moffitt, F. H. and Mikhail, E. M., 1980. Photogrammetry. Harper [and] Row, New York.

Peterman, V., 2010. DLT Based Approach for Deformation Measurement. International Archives of Photogrammetry, Remote Sensing and Spatial Information Sciences, Vol. XXXVIII, Part 5, Commission V Symposium (pp. 502-504). Newcastle: ISPRS.

Photometrix. 2004. Australis - User Manual. (www.photometrix.com.au)
Ratner, L.W., 2003. Non-Linear Theory of Elasticity and Optimal Design. Elsevier Science. doi:10.1016/B978044451427-1/50005-0

Triggs B., McLauchlan P.F., Hartley R.I., Fitzgibbon A.W. (2000) Bundle Adjustment - A Modern Synthesis. In: Triggs B., Zisserman A., Szeliski R. (eds) Vision Algorithms: Theory and Practice. IWVA 1999. Lecture Notes in Computer Science, vol 1883. Springer, Berlin, Heidelberg. https://doi.org/10.1007/3540-44480-7_21

Wolf, P. R., 2000. Elements of Photogrammetry: With Applications in GIS. s.l.:McGraw-Hill.

Xiao, R., Shi, H., He, X., Li, Z., Jia, D., Yang, Z., 2019. Deformation Monitoring of Reservoir Dams using GNSS: An Application to South-to-North Water Diversion Project, China. IEEE Access, 1-1. doi:10.1109/access.2019.2912143

Zeitler, W., Doerstel, C., Jacobsen, K., 2002. Geometric Calibration of the DMC: Method and Results. ISPRS Archives Volume XXXIV Part 1. 